\title{
Surveying uveitis specialists-a call for consensus
}

\author{
Emmett T. Cunningham Jr.
}

Received: 26 January 2012 / Accepted: 30 January 2012 / Published online: 28 March 2012

(C) The Author(s) 2012. This article is published with open access at SpringerLink.com

In the early 1990s, former Michigan supreme court Justice Thomas Brennan became disillusioned with popular law school rankings and so decided to survey 100 academics, judges, and lawyers on his own, asking them to rank a list of ten schools he provided. He used a composite index similar in structure, but different in content, to those used by mainstream surveyors, such as U.S. News \& World Report. As expected, many of the big name schools-Harvard, Yale, Stanford - made it to the top of the list. Penn State, as Brennan recalled, "[Was] about in the middle of the pack. Maybe fifth among the 10 schools listed." There was one small problem, however. Penn State had no law school at the time. Brennan had included it to make a point: surveys are limited by both the quality of the questions asked and by how familiar respondents are with the subject being surveyed $[1,2]$.

Similar surveys using questionnaires are employed commonly in medicine and, when well-designed and implemented, can provide valuable information regarding perceptions, preferences, and practice patterns - a finger on the pulse, if you will, of current treatment approaches [3, 4]. Almost without

\footnotetext{
E. T. Cunningham Jr.

California Pacific Medical Center,

San Francisco, CA, USA

E. T. Cunningham Jr.

Department of Ophthalmology,

Stanford University School of Medicine,

Stanford, CA, USA

E. T. Cunningham Jr. $(\bowtie)$

West Coast Retina Medical Group,

185 Berry Street, Lobby 2, Suite 130,

San Francisco, CA 94107, USA

e-mail: emmett_cunningham@yahoo.com
}

exception, variation is the rule in such surveys. Engstrom and colleagues, for example, published in 1991 the results of a survey of 62 treating uveitis specialists in the American Uveitis Society (AUS) regarding what were then current practices in the management of ocular toxoplasmosis [5]. While a sizable proportion of respondents viewed poor vision $(<20 / 200)$, marked or severe vitreous inflammation, and zone 1 lesion location [6] as absolute indications for antimicrobial therapy, the extent to which experts reached agreement regarding when to initiate treatment was by no means absolute. Moreover, the lack of consensus was even more striking when considering which agent(s) to choose. Specifically, experts reported use of ten different antimicrobial drugs in more than four different combinations, with approximately one third recommending a combination containing pyrimethamine, folinic acid, sulfadiazine, and prednisone. Holland and Lewis updated this survey in 2002, publishing the results gathered from 79 respondents who evaluated and managed patients with ocular toxoplasmosis [7]. Similar "absolute treatment indicators" were identified, but this time 11 different agents were used in an equal number of combinations, including some not mentioned in the 1991 survey. Once again, the most common approach involved the combined use of pyrimethamine, folinic acid, sulfadiazine, and prednisone - although more than two thirds recommended other single or combination agent treatment regimens. Similar trends and variations in treatment approach were observed when uveitis specialists were surveyed in 2011 by Wakefield and associates [8] - fully 20 years after the original ocular toxoplasmosis practice survey was published. Even greater variation regarding indicators of treatment exists among nonuveitis specialists [9].

One thing well-designed surveys of medical practitioners can do particularly well is identify limitations and deficiencies in the level and understanding of current clinical knowledge, 
including familiarity with and adherence to published guidelines. This was nicely demonstrated by Nguyen and colleagues in 2010, when the authors published the results of a survey regarding treatment of noninfectious uveitis as reported by 60 ophthalmologists and three rheumatologists [10]. Striking among the reported findings was the extent to which treatment patterns differed from recommended guidelines published by an expert panel roughly 10 years prior [11]. This was particularly so regarding the long-term use of oral corticosteroids, which tended to be used at doses three to four times the recommended maximal dose for chronic therapy of $10 \mathrm{mg} /$ day. Similarly striking was the use of corticosteroid sparing agents, which were introduced to lower systemic corticosteroid doses to or below $10 \mathrm{mg} /$ day in only $12 \%$ of patients. In fact, $75 \%$ of surveyed physicians did not use and were not aware of the existence of uveitis treatment guidelines. Among the ophthalmologists surveyed by Nguyen and associates, only 19 (32\%) were uveitis specialists, however, and so these results undoubtedly reflected the biases and practice patterns of the particular population surveyed.

In this issue of the Journal of Ophthalmic Inflammation and Infection, Esterberg and Acharya provide additional insights into the use of corticosteroid-sparing immunomodulatory therapy for chronic noninfectious uveitis [12]. The authors summarize responses from a group of 45 uveitis specialists identified electronically using the AUS and Proctor Foundation e-mail LISTSERVs. Sixty-eight percent of respondents practiced in a university or academic setting and $73 \%$ had 6 or more years experience treating uveitis. One might presume, therefore, that the vast majority of the participants had both knowledge and experience regarding previously published uveitis treatment guidelines [11]. This view is supported by the fact that the median acceptable maintenance dose of oral prednisone reported by the respondents was $7.5 \mathrm{mg} /$ day and was in all instances at or less than the $10 \mathrm{mg} /$ day recommended by these same guidelines. A number of interesting observations were made by the authors. First, antimetabolites, most notably methotrexate and mycophenolate mofetil, tended to be the most preferred and first used immunosuppressive agents despite only modest effectiveness, both perceived [12] and actual — at least as measured by control of inflammation and corticosteroid-sparing success rates [13-15]. This approach appears to have come from complex considerations regarding cost, ease of administration, and availability of long-term efficacy and tolerability data. Conversely, the alkylating agent cyclophosphamide and the TNF- $\alpha$ inhibitors were both less preferred and less frequently used, despite higher perceived effectiveness. Concerns seemed to center around safety/tolerability in the case of cyclophosphamide, whereas cost, lack of long-term data, and to a lesser extent ease of administration were the major reasons for not prescribing TNF- $\alpha$ inhibitors. Respondents were not queried regarding the use of chlorambucil [16-18], etanercept [19-23] or the interferons [24, 25] despite reports of therapeutic benefit with these agents in selected patients with uveitis. Second, the most favored agent for the treatment of intermediate and posterior/panuveitis was mycophenolate mofetil, a preference supported at least in part by high success rates with this agent in the Systemic Immunosuppressive Therapy for Eye (SITE) Diseases Cohort Study [14, 15, 26]. Third, azathioprine was generally the least favored antimetabolite regardless of anatomical localization of the inflammation, despite the fact that a number of randomized trials comparing azathioprine to methotrexate in various rheumatologic diseases and to prevent organ rejection post-transplantation have shown similar efficacy and tolerability [12]. And fourth, cyclosporine, the only leukocyte signaling inhibitor queried, was rarely preferred and infrequently used, due primarily to concerns over tolerability. Such perceptions appear to be supported, at least partially, by the findings of the SITE Study group, which reported relatively low corticosteroid sparing success with cyclosporine $[15,27]$. Moreover, adverse events tend to increase with age in patients treated with cyclosporine and are particularly common in the elderly [27].

Taken together, published practice surveys in uveitis highlight several important points. First is the need for improved education and wider dissemination of evidencebased reviews regarding uveitis treatment-particularly to non-specialists who care for a sizable proportion of patients with uveitis [28]. Second is the importance of practical and timely treatment guidelines promulgated by those most knowledgeable in the field - either as expert panel recommendations [11] or true consensus guidelines [29]. Perhaps surprisingly, such treatment recommendations or guidelines do not yet exist for ocular toxoplasmosis - the most common cause of infectious uveitis worldwide [30, 31], and while guidelines do exist regarding the use of immunosuppressive drugs in patients with noninfectious uveitis, they are largely unknown by all but those already quite experienced in the use of such agents. Moreover, current treatment guidelines for uveitis are more than 10 years old, provide little information regarding treatment goals or endpoints when using individual or combined therapies to treat specific conditions or complications of uveitis, and include relatively little mention of the newer biologic agents. It is perhaps time, therefore, to consider introducing evidencebased treatment recommendations or guidelines for ocular toxoplasmosis and updating existing guidelines on the use of immunomodulatory agents to treat ocular inflammatory disease, including recent data on the use of TNF- $\alpha$ inhibitors and the interferons. And third is the importance of standardized outcome metrics in uveitis treatment studies [15]. Perceptions and preferences are noteworthy, but are by no means substitutes for data obtained from well-designed studies, be they retrospective and observational or, when feasible and appropriate, prospective and randomized. 
Acknowledgments Supported in part by The Pacific Vision Foundation and The San Francisco Retina Foundation. I thank Dr. Nisha R. Acharya and Dr. Gary N. Holland for thoughtfully reading and commenting on an early version of this editorial.

Financial conflicts The author has no financial conflicts.

Open Access This article is distributed under the terms of the Creative Commons Attribution License which permits any use, distribution, and reproduction in any medium, provided the original author(s) and the source are credited.

\section{References}

1. Gibeaut J (1996) Rank speculation. Some big-name law schools fare poorly in new, controversial by a former Michigan justice. ABA J $42-43$

2. Gladwell M (2011) The order of things. What college rankings really tell us. The New Yorker, February $14 \& 21,2011,68-75$

3. McColl E, Jacoby A, Thomas L, Soutter J, Bamford C, Steen N, Thomas R, Harvey E, Garratt A, Bond J (2001) Design and use of questionnaires: a review of best practices applicable to surveys of health service staff and patients. Health Technol Assess 5-31

4. Hing CB, Smith TO, Hooper L, Song F, Donell ST (2011) A review of how to conduct a surgical survey using a questionnaire. Knee 18(4):209-213

5. Engstrom RE Jr, Holland GN, Nussenblatt RB, Jabs DA (1991) Current practices in the management of ocular toxoplasmosis. Am J Ophthalmol 111(5):601-610

6. Cunningham ET Jr, Hubbard LD, Danis RP, Holland GN (2011) Proportionate topographic areas of retinal zones 1,2, and 3 for use in describing infectious retinitis. Arch Ophthalmol 129(11):1507-1508

7. Holland GN, Lewis KG (2002) An update on current practices in the management of ocular toxoplasmosis. Am J Ophthalmol 134 (6): $102-114$

8. Wakefiled D, Cunningham ET Jr, Pavesio C, Garweg JG, Zierhut M (2011) Controversies in ocular toxoplasmosis. Ocul Immunol Inflamm 19(1):2-9

9. Lum F, Jones JL, Holland GN, Liesegang TJ (2005) Survey of ophthalmologists about ocular toxoplasmosis. Am J Ophthalmol 140(4):724-727

10. Nguyen QD, Hatef E, Kayen B, Macahilig CP, Ibrahim M, Wang J, Shaikh O, Bodaghi B (2011) A cross-sectional study of the current treatment patterns in noninfectious uveitis among specialists in the United States. Ophthalmology 118(1):184-190

11. Jabs DA, Rosenbaum JT, Foster CS, Holland GN, Jaffe GJ, Louie JS, Nussenblatt RB, Stiehm ER, Tessler H, Van Gelder RN, Whitcup SM, Yocum D (2000) Guidelines for the use of immunosuppressive drugs in patients with ocular inflammatory disorders: recommendations of an expert panel. Am J Ophthalmol 130:492-513

12. Esterberg E, Acharya NR (2011) Corticosteroid-sparing therapy: practice patterns among uveitis specialists. J Ophthalmic Inflamm Infect (in press)

13. Gangaputra S, Newcomb CW, Liesegang TL, Kaçmaz RO, Jabs DA, Levy-Clarke GA, Nussenblatt RB, Rosenbaum JT, Suhler EB, Thorne
JE, Foster CS, Kempen JH (2009) Systemic Immunosuppressive Therapy for Eye Diseases Cohort Study. Methotrexate for ocular inflammatory diseases. Ophthalmology 116(11):2188-98.e1

14. Daniel E, Thorne JE, Newcomb CW, Pujari SS, Kaçmaz RO, Levy-Clarke GA, Nussenblatt RB, Rosenbaum JT, Suhler EB, Foster CS, Jabs DA, Kempen JH (2010) Mycophenolate mofetil for ocular inflammation. Am J Ophthalmol 149(3):423-432.e1-2

15. Cunningham ET Jr, Goldstein DA, Zierhut M. Uveitis treatment trials - A cross trial perspectives. Ocul Immunol Inflamm 2012; 20(2):63-67

16. Goldstein DA, Fontanilla FA, Kaul S, Sahin O, Tessler HH (2002) Long-term follow-up of patients treated with short-term high-dose chlorambucil for sight-threatening ocular inflammation. Ophthalmology 109:370-377

17. Birnbaum AD, Oh F, Sahin O, Little DM, Tessler HH, Goldstein DA (2010) Chlorambucil and malignancy. Ophthalmology 117 (7):1466-1466.e1

18. Zaghetto JM, Yamamoto MM, Souza MB, Silva FT, Hirata CE, Olivalves E, Yamamoto JH (2010) Chlorambucil and cyclosporine A in Brazilian patients with Behçet's disease uveitis: a retrospective study. Arq Bras Oftalmol 73(1):40-46

19. Rosenbaum JT (2010) Future of biological therapy for uveitis. Curr Opin Ophthalmol 21(6):473-477

20. Hemmati HD, Dunn JP (2010) Biologic therapy for uveitis. Expert Rev Ophthalmol 5(2):225-239

21. Lee FF, Foster CS (2010) Pharmacotherapy of uveitis. Expert Opin Pharmacother 11(7):1135-1146

22. Heiligenhaus A, Thurau S, Hennig M, Grajewski RS, Wildner G (2011) Anti-inflammatory treatment of uveitis with biologicals: new treatment options that reflect pathogenetic knowledge of the disease. Graefes Arch Clin Exp Ophthalmol 248(11):1531-1551

23. Larson T, Nussenblatt RB, Sen HN (2011) Emerging drugs for uveitis. Expert Opin Emerg Drugs 16(2):309-322

24. Benitah NR, Sobrin L, Papaliodis GN (2011) The use of biologic agents in the treatment of ocular manifestations of Behcet's disease. Semin Ophthalmol 26(4-5):295-303

25. Deuter CM, Zierhut M, Möhle A, Vonthein R, Stöbiger N, Kötter I (2010) Long-term remission after cessation of interferon- $\alpha$ treatment in patients with severe uveitis due to Behçet's disease. Arthritis Rheum 62(9):2796-2805

26. Galor A, Jabs DA, Leder HA, Kedhar SR, Dunn JP, Peters GB 3rd, Thorne JE (2008) Comparison of antimetabolite drugs as corticosteroid-sparing therapy for noninfectious ocular inflammation. Ophthalmology 115(10):1826-1832

27. Kaçmaz RO, Kempen JH, Newcomb C, Daniel E, Gangaputra S, Nussenblatt RB, Rosenbaum JT, Suhler EB, Thorne JE, Jabs DA, Levy-Clarke GA, Foster CS (2010) Cyclosporine for ocular inflammatory diseases. Ophthalmology 117(3):576-584

28. Smith JR, Jabs DA, Briceland DJ, Holland GN (2008) Education in the ophthalmic discipline of uveitis. Am J Ophthalmol 146 (6):799-801

29. Vakil N (2011) Consensus guidelines: method or madness? Am J Gastroenterol 106(2)S:225-227

30. Holland GN (2003) Ocular toxoplasmosis: a global reassessment. Part I: epidemiology and course of disease Am J Ophthalmol 136 (6):973-988

31. Holland GN (2004) Ocular toxoplasmosis: a global reassessment. Part II: disease manifestations and management Am J Ophthalmol 137(1):1-17 